\title{
QUALITATIVE AND QUANTITATIVE COMPARISON OF TWO PROMISING OXY-FUEL POWER CYCLES FOR $\mathrm{CO}_{2}$ CAPTURE
}

\author{
W. Sanz, H. Jericha, B. Bauer, E. Göttlich \\ Institute for Thermal Turbomachinery and Machine Dynamics \\ Graz University of Technology, Graz, Austria \\ wolfgang.sanz@tugraz.at
}

\begin{abstract}
Since the Kyoto conference there is a broad consensus that the human emission of greenhouse gases, mainly $\mathrm{CO}_{2}$, has to be reduced. In the power generation sector there are three main alternatives which are currently studied world wide. Among them oxy-fuel cycles with internal combustion with pure oxygen are a very promising technology.

Within the European project ENCAP - ENhanced $\mathrm{CO}_{2}$ CAPture - the benchmarking of a number of novel power cycles with $\mathrm{CO}_{2}$ capture was carried out [1]. Within the category oxy-fuel cycles the Graz Cycle and the Semi-Closed Oxy-Fuel Combustion Combined Cycle (SCOC-CC) both achieved a net efficiency of nearly $50 \%$. In a second step a qualitative comparison of the critical components was performed according to their technical maturity. In contrast to the Graz Cycle the study authors claimed that no major technical barriers would exist for the SCOC-CC.

In this work the ENCAP study is repeated for the SCOCCC and for a modified Graz Cycle variant as presented at the ASME IGTI conference 2006 [2]. Both oxy-fuel cycles are thermodynamically investigated based on common assumptions agreed with industry in previous work. The calculations showed that the high-temperature turbine of the SCOC-CC plant needs a much higher cooling flow supply due to the less favorable properties of the working fluid. A layout of the main components of both cycles is further presented which shows that both cycles rely on the new designs of the hightemperature turbine and the compressors. The SCOC-CC compressor needs more stages due to a lower rotational speed but has a more favorable operating temperature. In general, all turbomachines of both cycles show similar technical challenges and are regarded as feasible.
\end{abstract}

\section{NOMENCLATURE}

$\mathrm{A}_{\mathrm{ax}}=$ flow cross section

$\mathrm{c}_{\mathrm{p}, \mathrm{c}}=$ heat capacity of cooling flow

$\mathrm{c}_{\mathrm{p}, \mathrm{g}}=$ heat capacity of main flow

$\mathrm{dQ}=$ differential convective heat transfer

$\mathrm{dT}_{1}=$ differential temperature decrease due to polytropic expansion

$\mathrm{dT}_{2}=$ differential temperature decrease due to convective cooling

$\mathrm{dm} \dot{\mathrm{c}}_{\mathrm{c}}=$ differential cooling mass flow

$\mathrm{f}=$ ratio of cooled surface to flow cross section

$\dot{\mathrm{m}}=$ main mass flow

$\dot{\mathrm{m}}_{\mathrm{c}}=$ total cooling mass flow of a partial turbine

$\mathrm{n}_{\mathrm{st}}=$ stage number of partial turbine

$\mathrm{Pr}=$ Prandtl number

$\mathrm{Q}_{\mathrm{st}}=$ stage convective heat transfer

$\mathrm{Re}=$ Reynolds number

St $=$ Stanton number

$\mathrm{T}=$ temperature of main gas flow

$\mathrm{T}_{\mathrm{c}}=$ temperature of inlet cooling mass flow

$\mathrm{T}_{\mathrm{m}}=$ allowable metal temperature

$\Delta \mathrm{T}_{1}=$ stage temperature difference due to polytropic expansion

$\mathrm{w}=$ velocity at blade row exit

$\alpha=$ heat transfer coefficient

$\beta=$ flow angle at blade row exit

$\rho=$ density

\section{INTRODUCTION}

In the last two years global warming, environmental change and destruction of natural resources like water and forest reserves have reached exasperating speed. Very little 
doubt remains regarding the effect and the extent of anthropologic contribution. Counter measures should be put into effect quickly and in all realms of human activity.

The main reason - the worldwide ever rising emission of greenhouse gases to atmosphere - has been recognized since 1988 by the 700 scientists who formulated the Call of Action of the Toronto Conference. Other events have followed and today the Kyoto Goal of reducing the global greenhouse gas emissions by a substantial amount compared to the 1990 emissions is acknowledged by the majority of governments around the world. The combustion generated gas $\mathrm{CO}_{2}$ and also the very active biologically emitted methane (melting Perma frost) are the most important contributors to atmospheric change and global warming.

Within the EU there is a strong pressure on utilities and industry to reduce the $\mathrm{CO}_{2}$ emissions from power generation. So several EU projects were funded within the Frame Program 6 which cope with carbon capture and storage (CCS). In September 2006 the first general assembly of the European Technology Platform ZEP on Zero Emission Fossil Fuel Power Plants (ETP ZEP [3]) was held, whose goal is the creation of highly efficient power plants with near-zero emissions by 2020 within the current Frame Program 7.

CCS is considered as an urgently needed short and mid term solution to curb the emissions from fossil fuel combustion before new and regenerative energy resources can take over. Technology leaders discuss three possibilities of $\mathrm{CO}_{2}$ capture on grand scale:

- Oxy-fuel systems with combustion of fossil fuels by pure oxygen leading to a working fluid of mainly $\mathrm{CO}_{2}$ and water. After separation of the water by proper condensation, the combustion generated $\mathrm{CO}_{2}$ can be retained, stored or used for other technical applications.

- Post-combustion capture of $\mathrm{CO}_{2}$ from exhaust gases by chemical means or membranes which appears up to now to be costly, ineffective in use of solvents and to lower air breathing gas turbine efficiency remarkably.

- Pre-combustion transformation of hydrocarbons especially natural gas or syngas from coal gasification into a mixture of $\mathrm{CO}_{2}$ and $\mathrm{H}_{2}$ from which the heat engine or gas turbine fuel $\mathrm{H}_{2}$ can be derived. $\mathrm{CO}_{2}$ is retained in the transformation process, separation is intended to be effected by solvents or by membranes.

Up to now it is not clear, which technology has the best chances to dominate future power generation, but it is expected they all will have their own application area. Within the project ENCAP (Enhanced $\mathrm{CO}_{2}$ Capture, [4]), a European Union funded research project with more than twenty partners from industry, government institutions and universities, several technologies for power generation that would meet the target of at least $90 \% \mathrm{CO}_{2}$ capture rate and $50 \% \mathrm{CO}_{2}$ capture cost reduction are investigated. A benchmarking of a number of precombustion and oxy-fuel types of cycles was carried out to identify the most promising candidates.

Among the oxy-fuel cycles investigated the highest efficiencies were reported for the S-Graz Cycle (48.9\%) and the Semi-Closed Oxy-Fuel Combustion Combined Cycle (SCOC-CC, [1]) (47.7 \%). Although the S-Graz Cycle turned out to achieve the highest efficiency, the value given by the ENCAP study is remarkably lower (by $3.6 \%$-points) than the one reported by Sanz et al. [5] probably due to different assumptions on losses and component efficiencies. Furthermore, a feasibility study of the key components was performed and they were classified according to their technology readiness and expected costs. In this analysis the SCOC-CC plant was evaluated technically favorable, whereas three components of the S-Graz Cycle plant were ranked as critical. This statement arises partly because not the latest version of the Graz Cycle as presented at the ASME 2006 [2] was investigated in the ENCAP study.

Because of the differences in efficiency between ENCAP and [5] and because of the new scheme of the Graz Cycle not considered in the study, the comparison between both plants is repeated in this work to give a correct picture. Both oxy-fuel cycles are thermodynamically investigated based on assumptions agreed with industry in previous work [5]. It is succeeded by a layout and discussion of the main components for a $400 \mathrm{MW}$ power plant.

In this work the nomination "Graz Cycle" means the "SGraz Cycle" as presented in [2].

\section{THERMODYNAMIC EVALUATION}

All thermodynamic simulations were performed using the commercial software IPSEpro by SIMTECH Simulation Technology [6]. This software allows to implement userdefined fluid properties to simulate the real gas properties of the cycle medium. The physical properties of water and steam are calculated using the IAPWS_IF97 formulations [7], $\mathrm{CO}_{2}$ is also modeled as real gas based on correlation of [8]. Furthermore, a simulation module was developed for the calculation of cooled turbines as described below.

The oxy-fuel system is suited for all kinds of fossil fuels, e.g. methane or syngas from coal or biomass gasification (for the Graz Cycle see [9, 10]). In this work thermodynamic data are presented for a cycle fired with methane with a lower heating value of $50015 \mathrm{~kJ} / \mathrm{kg}$.

The component efficiencies and losses were agreed with the Norwegian oil and gas company Statoil ASA in the course of a thermodynamic evaluation of the Graz Cycle and can be found in [5]. Some important assumptions are listed here again: 1) The isentropic efficiency of the cooled gas turbines is $90.3 \%$ and includes the flow losses due to cooling. It corresponds to a polytropic efficiency of $85.5 \%$. The demand of cooling flow is calculated as described below. 2) Oxygen production is considered with an effort of $900 \mathrm{~kJ} / \mathrm{kg}(0.25 \mathrm{kWh} / \mathrm{kg})$, the compression needs $325 \mathrm{~kJ} / \mathrm{kg}$. 3) The compression of combustion generated $\mathrm{CO}_{2}$ to 100 bar is considered in the power balance with a value of $310 \mathrm{~kJ} / \mathrm{kg} \mathrm{CO}_{2}$ for the Graz Cycle and with $350 \mathrm{~kJ} / \mathrm{kg}$ for the SCOC-CC plant, since in the Graz Cycle compression starts at 1.7 bar compared to 1 bar for the SCOC-CC. 


\section{Simulation of a Cooled Gas Turbine}

The outcome of this thermodynamic study largely depends on the different demand of gas turbine cooling flow for both cycles, so that the simulation model of the cooled gas turbine is explained in detail. A simple stage-by-stage approach similar to the first model in [11] is applied which allows to calculate the amount of cooling steam.

In a gas turbine the decrease in temperature stems from the expansion process, from the convective cooling of the main flow at the "cold" blade surfaces and from the mixing of the cooling flow with the main flow. The convective heat transfer to the cold blade surfaces in a stage is

$$
\mathrm{Q}_{\mathrm{st}}=\mathrm{f} \mathrm{A}_{\mathrm{ax}} \alpha\left(\mathrm{T}-\mathrm{T}_{\mathrm{m}}\right)
$$

By relating to the stage temperature decrease due to polytropic expansion $\Delta \mathrm{T}_{1}$ the differential convective heat transfer can be calculated (Eq. (2)). It leads to a differential temperature decrease of the main gas flow $\mathrm{dT}_{2}$ :

$$
\begin{aligned}
& \mathrm{dQ}=\mathrm{Q}_{\mathrm{st}} / \Delta \mathrm{T}_{1} \mathrm{dT}_{1} \\
& \mathrm{dQ}=\dot{\mathrm{m}} \mathrm{c}_{\mathrm{p}, \mathrm{g}} \mathrm{dT}_{2}=\rho \mathrm{w} \sin \beta \mathrm{A}_{\mathrm{ax}} \mathrm{c}_{\mathrm{p}, \mathrm{g}} \mathrm{dT}_{2}
\end{aligned}
$$

Thus following relationship between the differential temperature decrease due to convective heat transfer and due to expansion can be derived:

$$
\mathrm{dT}_{2}=\frac{\mathrm{T}-\mathrm{T}_{\mathrm{m}}}{\Delta \mathrm{T}_{1}} \mathrm{fSt} \frac{1}{\sin \beta} \mathrm{dT}_{1}
$$

with $S t=\frac{\alpha}{\rho c_{p, g} W}$ as Stanton number.

The heat transferred to the blades is absorbed by the internal cooling mass flow which is heated to a temperature $\Delta \mathrm{T}_{\mathrm{d}}$ below the metal temperature $\mathrm{T}_{\mathrm{m}}$.

$$
\mathrm{dQ}=\mathrm{dm}_{\mathrm{c}} \mathrm{c}_{\mathrm{p}, \mathrm{c}}\left(\mathrm{T}_{\mathrm{m}}-\Delta \mathrm{T}_{\mathrm{d}}-\mathrm{T}_{\mathrm{c}}\right)
$$

This allows to determine the differential demand of cooling mass flow depending on the differential temperature drop due to polytropic pexpansion:

$$
\mathrm{dm}_{\mathrm{c}}=\dot{\mathrm{m}} \frac{\mathrm{c}_{\mathrm{p}, \mathrm{g}}}{\mathrm{c}_{\mathrm{p}, \mathrm{c}}} \frac{\mathrm{T}-\mathrm{T}_{\mathrm{m}}}{\mathrm{T}_{\mathrm{m}}-\Delta \mathrm{T}_{\mathrm{d}}-\mathrm{T}_{\mathrm{c}}} \mathrm{fSt} \frac{1}{\sin \beta} \frac{\mathrm{dT}_{1}}{\Delta \mathrm{T}_{1}}
$$

Within the thermodynamic simulation with IPSEpro integration of Eq.(6) is done for partial turbines using mean values denoted by an overbar:

$$
\dot{\mathrm{m}}_{\mathrm{c}}=\dot{\mathrm{m}} \frac{\overline{\mathrm{c}_{\mathrm{p}, \mathrm{g}}}}{\overline{\mathrm{c}_{\mathrm{p}, \mathrm{c}}}} \frac{\overline{\mathrm{T}}-\mathrm{T}_{\mathrm{m}}}{\mathrm{T}_{\mathrm{m}}-\Delta \mathrm{T}_{\mathrm{d}}-\mathrm{T}_{\mathrm{c}}}\left(\overline{\mathrm{f}} \mathrm{n}_{\mathrm{st}}\right) \overline{\mathrm{St}} \frac{1}{\sin \bar{\beta}}
$$

Since both cycles use very different working and cooling fluids (steam vs. $\mathrm{CO}_{2}$ ), their properties have to be considered in the determination of the cooling mass flow demand. The heat capacities are calculated from the physical fluid properties, so that for similar turbomachinery design parameters (see below) only the differences in Stanton number have to be considered. Louis [12] suggested following correlation to calculate the Stanton number for the convective heat transfer on the hot side of a gas turbine blade:

$$
\mathrm{St}=0.5 \operatorname{Re}^{-0.37} \operatorname{Pr}^{-2 / 3}
$$

Eq. (8) is evaluated for the working fluids of both cycles in the temperature range of $600^{\circ} \mathrm{C}$ to $1000^{\circ} \mathrm{C}$ (where Prandtl number and viscosity data were available), and it was found that the Stanton number for the high-temperature turbine HTT of the Graz Cycle is by $7 \%$ higher than for the SCOC-CC for a speed of $3000 \mathrm{rpm}$. But for the fast-running first two stages of the Graz Cycle HTT (see below), the Stanton number is by 15 $\%$ lower. Because of the large uncertainty in the evaluation of the Stanton number, for the thermodynamic simulation the same Stanton number of 0.0041 (found by analysis of airbreathing gas turbines) was used for all cooled gas turbines in both cycles. But considering the estimates for the Stanton number according to Eq. (8) would result in a lower cooling flow demand for the Graz Cycle than calculated.

A comparative calculation of one high-temperature stage using the same parameters showed that the favorable heat capacities of the Graz Cycle working and cooling fluid lead to a $20 \%$ lower demand of cooling mass flow.

The contribution of the cooling mass flow to the total expansion work is considered on a stage-by-stage basis. Half of the stage cooling mass flow contributes to the stage expansion work, the rest is added at stage exit.

\section{Graz Cycle Scheme}

The basic principle of the so-called Graz Cycle has been developed by H. Jericha in 1985 [13] for solar generated oxygen-hydrogen fuel, in 1995 changed to fossil fuels [14, 15]. This was a first proposal for this type of oxy-fuel power cycle with $\mathrm{CO}_{2}$ capture. Improvements and further developments since then were presented at several conferences [9, 10, 16-19]. Any fossil fuel gas is proposed to be combusted with oxygen so that neglecting small impurities only the two combustion products $\mathrm{CO}_{2}$ and $\mathrm{H}_{2} \mathrm{O}$ are generated. The cycle medium of $\mathrm{CO}_{2}$ and $\mathrm{H}_{2} \mathrm{O}$ allows an easy and cost-effective $\mathrm{CO}_{2}$ separation by condensation. Furthermore, the oxygen combustion enables a power cycle with a thermal efficiency higher than for state-ofthe-art combined cycles plants, thus largely compensating the additional efforts for oxygen production.

The Graz Cycle plant as presented in [5] and investigated in the ENCAP study suffers from the disadvantages of the working fluid expansion into vacuum (very large and expensive condenser, corrosion risk for low pressure turbine with exit below dew point temperature). Therefore at the ASME IGTI conference 2006 in Barcelona [2] it was suggested according to the Austrian patent of the Graz Cycle [20] to condense the working fluid at atmospheric pressure, separate the combustion generated $\mathrm{CO}_{2}$ and use the condensation heat for evaporation in a bottoming steam cycle. Figure 1 shows the principle flow of this Graz Cycle variant with the main cycle data.

Basically the Graz Cycle consists of a high-temperature cycle (compressors C1 and C2, combustion chamber, HighTemperature Turbine HTT, Heat Recovery Steam Generator HRSG and High Pressure Turbine HPT) and a low temperature cycle (Low Pressure Turbine LPST, condenser and compressors C3 and C4). The fuel together with the nearly 


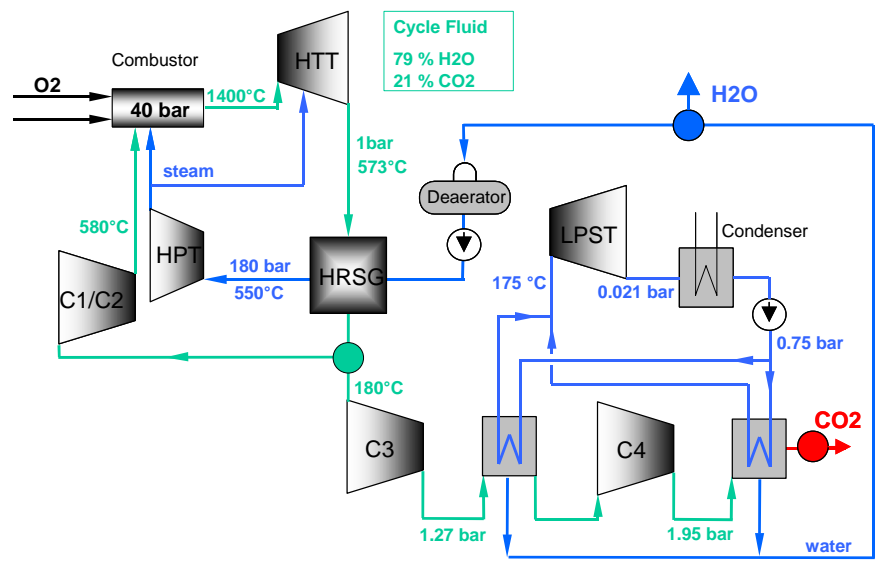

Fig. 1: Principle flow scheme of modified Graz Cycle power plant with condensation/evaporation in 1 bar range [2]

stoichiometric mass flow of oxygen is fed to the combustion chamber, which is operated at a pressure of 40 bar. Steam drives the burner vortex core bringing together the reaction components. The high flame temperature is further reduced by the inflow of the working gas $\left(\mathrm{CO}_{2} / \mathrm{H}_{2} \mathrm{O}\right)$ around the burners and into the combustion chamber liner.

A mixture of about $75.5 \%$ steam, $24 \% \mathrm{CO}_{2}, 0.4 \% \mathrm{O}_{2}$ and $0.1 \% \mathrm{~N}_{2}$ (mass fractions) leaves the combustion chamber at a mean temperature of $1400^{\circ} \mathrm{C}$, a value exceeded by $\mathrm{G}$ and $\mathrm{H}$ class turbines nowadays. The fluid is expanded to a pressure of 1.06 bar and $580^{\circ} \mathrm{C}$ in the HTT. Cooling is performed with steam coming from the HPT at about $330^{\circ} \mathrm{C}(13.7 \%$ of the HTT inlet mass flow), increasing the steam content to $78.4 \%$ at the HTT exit. The hot exhaust gas is cooled in the following HRSG to vaporize and superheat steam for the HPT; the pinch point of the HRSG is $5^{\circ} \mathrm{C}$ (an aggressive value but used for both cycles), the approach point at the superheater exit is $25^{\circ} \mathrm{C}$. After the HRSG about $55 \%$ of the cycle mass flow is recompressed using the main cycle compressors C1 and C2 with intercooler and is fed to the combustion chamber with a maximum temperature of $580^{\circ} \mathrm{C}$.

The remaining mass flow which contains the combustion generated $\mathrm{CO}_{2}$ is fed to a condensation process in the 1 bar range in order to avoid the problems described above. The heat content in the flow is still quite high so re-evaporation and expansion in a bottoming cycle is mandatory. For proper reevaporation two sections of working fluid condensations are provided, each following a compressor stage with reasonable increase of flow pressure resulting in a higher partial condensation pressure of the water content. The two compressor stages can be regarded as pre-runners of the $\mathrm{CO}_{2}$ delivery compressor and will be helpful in cleaning the turbomachinery, piping and HRSG interior from air in preparation of a cold start. The heat exchangers are well developed modern boiler elements providing steam just below atmosphere (0.75 bar) for the condensing steam turbine LPST.

At the first pressure level of 1.27 bar about $63 \%$ of the water content can be segregated, so that the power demand of the second compression stage is considerably reduced. It compresses up to 1.95 bar, which allows the segregation of further $25 \%$ of the contained water. Further cooling of the working fluid, also for water preheating, leads to the separation of additional $11 \%$, so that the water content of the $\mathrm{CO}_{2}$ stream which is supplied after pressure losses at 1.7 bar for further compression, is below $1 \%$. More details of the condensation/ evaporation process can be found in [2]. After segregation of the water stemming from the combustion process, the water flow is degassed in the deaerator with steam extracted after the HPT and fed to the HRSG for vaporization and superheating. The steam is then delivered to the HPT at 180 bar and $550{ }^{\circ} \mathrm{C}$. After the expansion it is used to cool the burners and the HTT stages. For transonic stages the authors suggest to use a special cooling system by transonic steam layers [21].

The two-step condensation/evaporation counteracts the effect of sinking $\mathrm{H}_{2} \mathrm{O}$ partial pressure due to condensed water extraction from working fluid and thus allows reasonable steam inlet conditions of 0.75 bar and $175^{\circ} \mathrm{C}$ at the LPST inlet. Expanding the steam to a condensation pressure of 0.021 bar for a cooling water temperature of $8^{\circ} \mathrm{C}$ (Northern Europe) provides about $72 \mathrm{MW}$ power output. A three-stage four-flow design is necessary to handle the high LPST volume flow for a 400 MW Graz Cycle plant.

The detailed flow sheet used for the thermodynamic simulation can be found in [2] and gives mass flow, pressure, temperature and enthalpy of all streams.

\section{Semi-Closed Oxy-Fuel Combustion Combined Cycle (SCOC-CC) Scheme}

In the ENCAP investigation the SCOC-CC plant turned out very promising because of its technical simplicity and relatively high efficiency [1]. Fig. 2 shows the principle flow scheme of the SCOC-CC.

Basically the SCOC-CC consists of a high-temperature Brayton cycle (High-Temperature Turbine HTT, combustion chamber, compressor C1 and Heat Recovery Steam Generator HRSG) with an unusual working fluid consisting mainly of $\mathrm{CO}_{2}$ and a conventional bottoming steam cycle (High Pressure Turbine HPT, Low Pressure Turbine LPT, condenser and feed pumps). The fuel together with the nearly stoichiometric mass flow of oxygen is fed to the combustion chamber, which is also operated at 40 bar. In SCOC-CC recycled $\mathrm{CO}_{2}$ is supplied to cool the burners and the liner.

This leads to quite a different working fluid leaving the combustion chamber at the same mean temperature of $1400^{\circ} \mathrm{C}$. It consists of about $92.5 \% \mathrm{CO}_{2}, 7.1 \%$ steam, $0.3 \% \mathrm{O}_{2}$ and 0.1 $\% \mathrm{~N}_{2}$ (mass fractions). The fluid is expanded to a pressure of 1.06 bar and $618^{\circ} \mathrm{C}$ in the HTT. Turbine cooling is performed with $\mathrm{CO}_{2}$ fed from the compressor $\mathrm{C} 1$ at $387^{\circ} \mathrm{C}$. But the necessary cooling mass flow is $30.5 \%$ of the HTT inlet mass flow and thus remarkably higher than the $13.7 \%$ needed for the Graz Cycle HTT. The reasons are less favourable heat capacities of working and cooling fluid consisting mainly of 


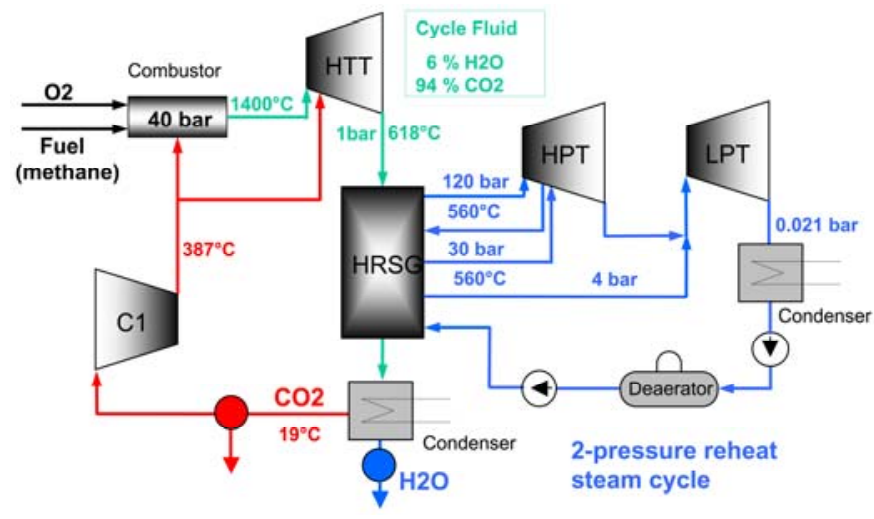

Fig. 2: Principle flow scheme of SCOC-CC

$\mathrm{CO}_{2}$, a higher cooling flow inlet temperature and a larger number of stages needed in the hot section as described in the chapter "Turbomachinery design". The higher cooling mass flow decreases the cycle efficiency by $1.8 \%$-points compared to a cycle with only $13.7 \%$ cooling mass flow demand. The cooling flow increases the $\mathrm{CO}_{2}$ content of the working fluid to $94 \%$ in the HTT.

In the following HRSG the hot exhaust gas is cooled to 65 ${ }^{\circ} \mathrm{C}$ vaporizing and superheating steam for the bottoming steam cycle. In the atmospheric condenser the working fluid is cooled to $18^{\circ} \mathrm{C}$, so that most of the combustion generated $\mathrm{H}_{2} \mathrm{O}$ can be extracted. The $\mathrm{CO}_{2}$ stream then has a purity of $98.8 \%$. After separation of the combustion generated $\mathrm{CO}_{2}$, it is fed to the compressor $\mathrm{C} 1$, where it is compressed to combustion pressure under continuous fluid extraction for cooling of the HTT.

The steam cycle is arranged as a double pressure reheat process for good efficiency. The live steam and reheat temperature is $560^{\circ} \mathrm{C}$. The pressure levels are set to $120 / 30 / 4$ bar similar to the ENCAP layout [1] which gives optimum efficiency for a minimum allowed humidity of $89 \%$ at the LPT exit (compared to $94 \%$ for the Graz Cycle). This low humidity is obtained for the same condenser pressure of 0.021 bar for a cooling water temperature of $8^{\circ} \mathrm{C}$.

The detailed flow sheet used for the thermodynamic simulation can be found in the appendix and gives mass flow, pressure, temperature and enthalpy of all streams.

\section{Thermodynamic Balance}

Table 1 gives a comparison of the power balance of the Graz Cycle plant and of the SCOC-CC for a $400 \mathrm{MW}$ net power output. The C1/C2 compressors of the Graz Cycle are compared with the $\mathrm{CO}_{2}$ compressor $\mathrm{C} 1$ of the SCOC-CC, since they both have the same task of working fluid compression. C3 and C4 compressors are only needed in the Graz Cycle. They help in start-up and can be regarded as pre-runners of $\mathrm{CO}_{2}$ recompression to 100 bar.

The Graz Cycle HTT has a lower mass flow, but a higher power output because of the higher heat capacity of steam. On the other side, in the SCOC-CC a higher portion of the total turbine power is provided by the steam cycle. The compression power is very similar for both cycles, with a slightly higher power demand of the $\mathrm{CO}_{2}$ compressor which has to compress all the cycle fluid. The net mechanical and electrical power is slightly higher for the SCOC-CC, but at the expense of a remarkably higher heat input. This results in a lower thermal efficiency and net electrical efficiency of about $3 \%$-points. Due to the higher fuel input needed, the efforts for oxygen supply and $\mathrm{CO}_{2}$ compression are higher for the SCOC-CC plant. Additionally, the higher $\mathrm{CO}_{2}$ segregation pressure of 1.7 bar in the Graz Cycle reduces the specific compression power from $350 \mathrm{~kJ} / \mathrm{kg}$ to $310 \mathrm{~kJ} / \mathrm{kg} \mathrm{CO}$. This results in a higher net efficiency of the Graz Cycle of 53.09 \% compared to $49.75 \%$ for the SCOC-CC plant.

In the ENCAP study the corresponding efficiencies were evaluated to $48.9 \%$ and $47.7 \%$ and thus differ remarkably from the values in this investigation. The reasons for the general higher efficiencies are mainly:

- Higher inlet temperature of oxygen and fuel of $150^{\circ} \mathrm{C}$, because it is expected that heat released from the air compression for the cryogenic air separation unit can be used for fuel and oxygen pre-warming.

- Oxygen is provided with $99 \%$ purity at an energy requirement of $0.25 \mathrm{kWh} / \mathrm{kg}$ compared to $95 \%$ purity at $0.30 \mathrm{kWh} / \mathrm{kg}$ in the ENCAP study. Even lower energy requirements are published in [22].

- Probably different assumptions of component efficiencies and losses, which are not published for the ENCAP project

Whereas the ENCAP study shows an advantage of the Graz Cycle of $1.2 \%$-points, in this work the difference is 3.35 $\%$-points. A difference of $1.8 \%$-points can be attributed to the higher cooling flow demand of the SCOC-CC HTT turbine

Table 1: Graz Cycle and SCOC-CC Power Balance

\begin{tabular}{|c|c|c|}
\hline & $\begin{array}{l}\text { Graz } \\
\text { Cycle }\end{array}$ & $\begin{array}{l}\text { SCOC- } \\
\text { CC }\end{array}$ \\
\hline HTT power [MW] & 623.6 & 557 \\
\hline HPT power [MW] & 47 & 95 \\
\hline LPST/LPT power [MW] & 72 & 95 \\
\hline Total turbine power $\mathrm{P}_{\mathrm{T}}[\mathrm{MW}]$ & 743 & 747 \\
\hline C1/C2 power $[\mathrm{MW}]$ & 220.2 & 235 \\
\hline C3/C4 power [MW] & 16.7 & \\
\hline Pump power [MW] & 4.3 & 3.5 \\
\hline Total compression power $\mathrm{P}_{\mathrm{C}}[\mathrm{MW}]$ & 241.2 & 238.5 \\
\hline $\begin{array}{l}\text { Net shaft power }[\mathrm{MW}] \\
\text { mechanical losses }\end{array}$ & 501.4 & 508.5 \\
\hline Total heat input $\mathrm{Q}_{\mathrm{zu}}[\mathrm{MW}]$ & 753.4 & 804.6 \\
\hline Thermal cycle efficiency [\%] & 66.55 & 63.20 \\
\hline $\begin{array}{l}\text { Electrical power output [MW] incl. } \\
\text { mechanical, electrical \& auxiliary loss }\end{array}$ & 487.4 & 494.5 \\
\hline Net electrical cycle efficiency [\%] & 64.70 & 61.45 \\
\hline $\mathrm{O}_{2}$ generation \& compression $\mathrm{P}_{\mathrm{O} 2}[\mathrm{MW}]$ & 74.3 & 78.6 \\
\hline Efficiency considering $\mathrm{O}_{2}$ supply [\%] & 54.84 & 51.68 \\
\hline $\mathrm{CO}_{2}$ compression to 100 bar $\mathrm{P}_{\mathrm{CO} 2}[\mathrm{MW}]$ & 13.1 & 15.5 \\
\hline Net power output [MW] & 400.0 & 400.0 \\
\hline Net efficiency $\eta_{\text {net }}[\%]$ & 53.09 & 49.75 \\
\hline
\end{tabular}


because of the lower heat capacity of the cooling gas and the need for more cooled stages (see below). It is not clear, if this effect is considered in the ENCAP study. A further difference stems from the higher efficiency of the modified Graz Cycle scheme as compared to the one used in the ENCAP study.

\section{TURBOMACHINERY DESIGN AND COMPARISON}

In the evaluation of different oxy-fuel concepts within the ENCAP project [1] the Graz Cycle variant investigated [5] showed three critical components:

- Working fluid condenser working at very low pressure bears the risk of corrosion and very low heat transfer, thus leading to high costs.

- The LPT turbine working with a steam/ $\mathrm{CO}_{2}$ mixture expands below the dew point thus leading to corrosion risks.

- The HTT needs a completely new design due to the working fluid.

The Graz Cycle presented in [2] avoids the first two problems, since condensation takes place at atmospheric pressure and the LPT is replaced by a low pressure steam turbine LPST. The HTT is the key component of the Graz Cycle as well as of the SCOC-CC plant, but the working fluid is very different. Whereas the Graz Cycle works mainly with steam, the SCOCCC working fluid is also unusual consisting mainly of $\mathrm{CO}_{2}$. Despite a new design is required for both turbines, in the ENCAP study the technical and economic barriers of the Graz Cycle HTT were seen larger, probably due to the high content of steam as a condensable fluid in the working and cooling medium.

In order to clarify the differences between the components of both cycles, in this work the design concept for a Graz Cycle power plant of $400 \mathrm{MW}$ electrical net output as described in [23] is compared with the turbomachinery layout of a SCOCCC plant of similar net power. The turbomachines are compared in respect to number of stages, stage dimensions and feasibility. For the layout of turbomachinery each manufacturer employs its own design philosophy regarding the optimum nondimensional parameters for the operating points. In this study the following common rules are applied for the turbomachinery layout of both cycles: 1) maximum relative inlet tip Mach number of 1.35 for compressors; 2) compressor work coefficient $\left(2 * \Delta \mathrm{H} / \mathrm{u}^{2}\right)$ of 0.814 [24]; 3) constant inner diameter and constant axial velocity throughout the compressors; 4) reaction type turbine blades with $50 \%$ degree of reaction at mid-section; 5) turbine work coefficient of close to 2 for optimum efficiency.

\section{Graz Cycle turbomachinery}

For the Graz Cycle plant the layout of turbomachinery has already been presented at the ASME IGTI conference 2006 [2] and slightly modified in [23]. Fig. 3 shows the arrangement of the main turbomachinery, its main parameters and dimensions are given in Table 2. A maximum tip Mach number of 1.35 at the inlet allows a rotational speed of $8500 \mathrm{rpm}$ for the C1

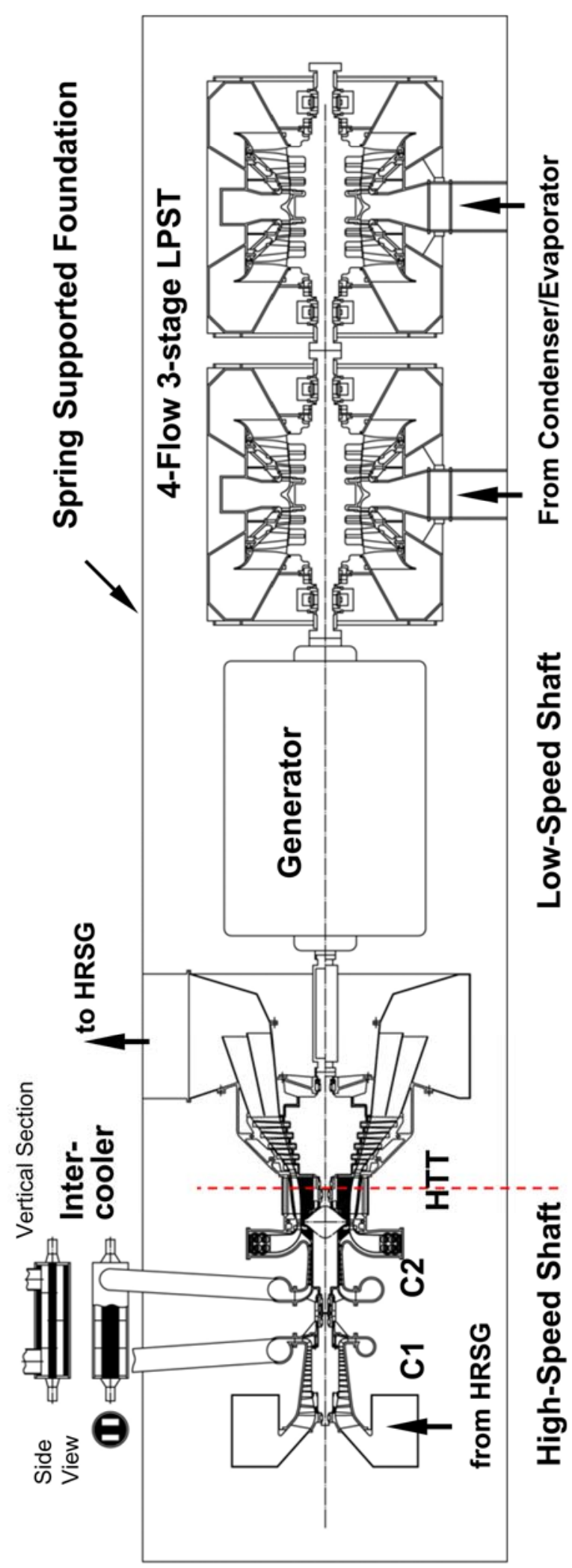

Fig. 3: Arrangement of the main turbomachinery for a $400 \mathrm{MW}$ Graz Cycle plant 
Table 2: Main Turbomachinery Dimensions for a 400 MW Graz Cycle Plant

\begin{tabular}{|l|l|r|r|r|r|}
\hline & & $\begin{array}{c}\text { HTT- } \\
\text { C }\end{array}$ & $\begin{array}{r}\text { HTT- } \\
\mathrm{P}\end{array}$ & C1* & C2 \\
\hline Inlet mass flow & $\mathrm{kg} / \mathrm{s}$ & 367 & 401 & 221 & 221 \\
\hline Inlet volume flow & $\mathrm{m}^{3} / \mathrm{s}$ & 61 & 156 & 309 & 43 \\
\hline Outlet mass flow & $\mathrm{kg} / \mathrm{s}$ & 401 & 417 & 221 & 221 \\
\hline Outlet volume flow & $\mathrm{m}^{3} / \mathrm{s}$ & 157 & 1263 & 46 & 18 \\
\hline Inlet mean diameter D & $\mathrm{m}$ & 1.065 & 1.77 & 1.037 & 0.95 \\
\hline Inlet inner diameter & $\mathrm{m}$ & 0.965 & 1.506 & 0.67 & 0.77 \\
\hline Inlet blade length l & $\mathrm{m}$ & 0.1 & 0.251 & 0.367 & 0.09 \\
\hline Inlet D/l & - & 10.6 & 6.5 & & \\
\hline Inlet $\mathrm{D}_{\text {in }} / \mathrm{D}_{\text {out }}$ & - & & & 0.48 & 0.81 \\
\hline Outlet mean diameter D & $\mathrm{m}$ & 1.14 & 3.107 & 0.882 & 0.85 \\
\hline Outlet inner diameter & $\mathrm{m}$ & 0.965 & 2.46 & 0.77 & 0.77 \\
\hline Outlet blade length l & $\mathrm{m}$ & 0.177 & 0.647 & 0.112 & 0.04 \\
\hline Outlet D/l & - & 6.46 & 4.8 & & \\
\hline Outlet $\mathrm{D}_{\text {in }} / \mathrm{D}_{\text {out }}$ & - & & & 0.77 & 0.9 \\
\hline Enthalpy drop & $\mathrm{kJ} / \mathrm{kg}$ & 582 & 978 & 590 & 379 \\
\hline Work coefficient & - & 2.2 & 2.5 & 0.814 & 0.814 \\
\hline Stage number & - & 2 & 5 & $6+\mathrm{R}$ & 7 \\
\hline Speed & $\mathrm{rpm}$ & 8500 & 3000 & 8500 & 8500 \\
\hline
\end{tabular}

* For C1 outlet dimensions are given for the last axial stage.

compressor. Therefore a two-shaft design for the HTT was chosen with a free-running compressor turbine HTTC driving the $\mathrm{C} 1$ and C2 compressors at $8500 \mathrm{rpm}$. This relatively high speed is selected for reason of obtaining sufficient blade length at outlet of $\mathrm{C} 2$ and to reduce the number of stages in both compressors as well as in the HTT. The second part of the HTT, the power turbine HTTP, delivers the main output to the generator at $3000 \mathrm{rpm}$. In a detailed study by a major gas turbine manufacturer ordered by Statoil ASA the feasibility of the two-shaft design was confirmed [5].

A further elongation of the shaft is done by coupling the four-flow LPST at the opposite side of the generator. The HPT can be coupled to the far end of the LPST or can drive a separate generator. A high-speed gear-drive steam turbine is proposed. The two shafts are based on the same spring supported foundation. The intercooler between C1 and C2 is located on the solid foundation.

\section{C1/C2 compressor design with intercooler:}

The rotational speed of $8500 \mathrm{rpm}$ of the C1 compressor leads to a high inlet tip Mach number, so that with the help of a slight positive inlet swirl an inlet Mach number of 1.33 is designed. The low hub to tip ratio at the inlet of 0.48 with a blade length of $367 \mathrm{~mm}$ leads to high centrifugal loads. Therefore a titanium blisk is suggested for the first rotor as shown in Fig. 4. Its radial elongation due to the centrifugal forces is carried by elastic axial rings which center the blisk and keep it on right angles to the shaft. The final radial wheel has to be milled separately from nickel alloy and is mounted to the main drum also by the same elastic ring design. The blading is a splitter vane design with axial inflow and radial outflow with
45 degree back-swept outlet. The wide vaneless diffuser and scroll improve the flow transfer to the intercooler. The drum rotor is made of ferritic steel and reaches only $390^{\circ} \mathrm{C}$. This design leads to only six axial and one radial stages for $\mathrm{C} 1$.

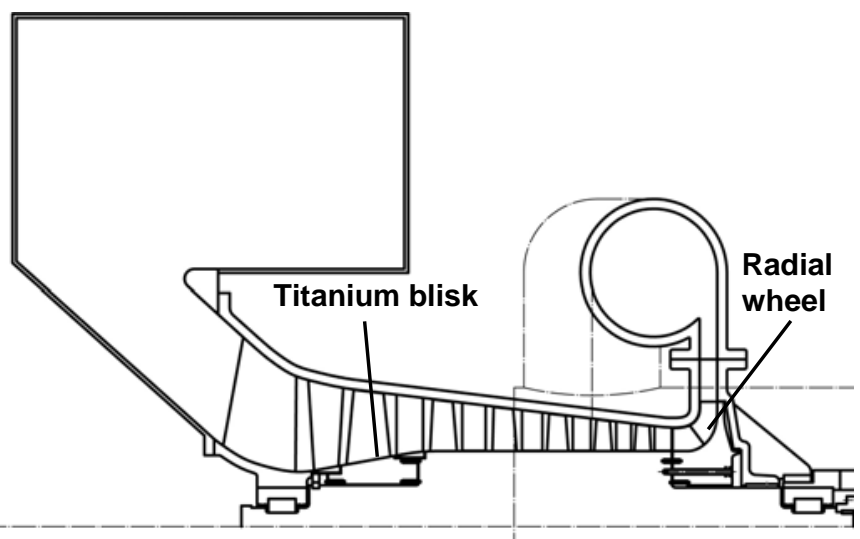

Fig. 4: C1 compressor with titanium blisk and radial last stage

For the rotor dynamics layout [23] the C1 drum rotor can be seen as symmetric shaft. The rotor passes at $0.622 \times 8500$ rpm its first critical speed under consideration of all masses and stiffnesses of the drum and of the bearing oil films. The second eigenfrequency is $16790 \mathrm{rpm}$ and is thus well above the operational speed. The arrangement of two bearings between C1 and C2 in double-wedge design serves to allow save passing of critical speed in both rotors. The operating speed distinctly above critical speed leads to self-centering of both rotors and allows very narrow tip gaps on the blading.

The inlet temperature to $\mathrm{C} 2$ is somewhat lowered by the intercooler but still reaches $380^{\circ} \mathrm{C}$. During course of compression the working fluid reaches an outlet temperature of $580^{\circ} \mathrm{C}$, so that from the second stage onwards cooling has to be applied on the rotor surface of the bladed annular flow channel. Seven axial stages with a stepwise decrease of blade length from 90 to $40 \mathrm{~mm}$ are supported on a drum rotor by an axial firtree root. The same design as used for the five center stages of $\mathrm{C} 1$ is also applied to the seven axial stages of C2. Fig. 5 shows the $\mathrm{C} 2$ rotor with the counter flow of cooling steam close to the

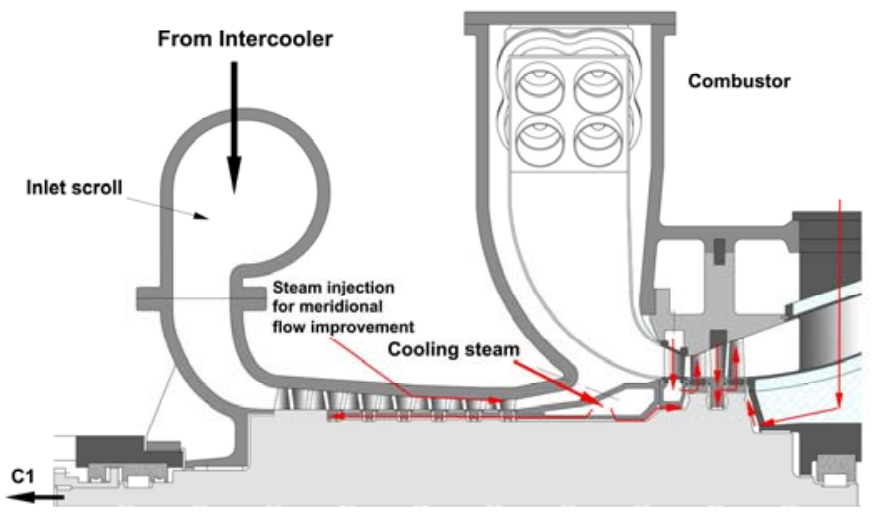

Fig. 5: Design of C2 drum rotor with cooling steam flow arrangement, combustor and HTTC 
drum surface. It is guided by means of openings under the blade roots and is sealed by strips carried on the guide vane diaphragms. By proper selection of the feed pressure this flow can be optimized at a small penalty in dilution of the main flow.

Excellent flow properties of this compressor can be expected due to its blade mounting on a drum rotor with optimized rotor dynamics enabling small radial tip clearances. The outlet hub to tip ratio is 0.9 .

\section{Turbine HTT:}

The same drum rotor carries not only the C2 but also the compressor turbine HTTC. The flow design of the HTTC will be a two-stage reaction turbine with $50 \%$ reaction at the mean section of both blade rows. The high rotor speed of $8500 \mathrm{rpm}$ as mentioned before provides for long blade lengths, i.e. a first stage blade of $100 \mathrm{~mm}$ and a second stage blade of $177 \mathrm{~mm}$ with an inner diameter of $965 \mathrm{~mm}$ (see Fig. 5).

The high speed and power of this turbine is made possible by ample steam cooling. Generally the authors rely on cooling by clean steam in all parts of blading and accessible surfaces of rotor drum. Nozzles and blades are cooled in conventional serpentine passage design with holes as shown in the cooling arrangement of Fig. 5. Rotor cooling steam is supplied along the whole drum surface. It is fed into a labyrinth seal in the inner range of the combustion chamber allowing the steam to flow to both sides. One flow is directed backwards under the dump diffuser into the outer surface of the C2 providing cooling steam as described above. The main amount of cooling steam flows along the rotor drum at the inner radius of the combustor casing towards the disk of the HTTC. More details of the cooling flow arrangement can be found in [2].

Alternatively the HTTC expansion could also be done with one transonic stage as shown in [2, 23]. This can be achieved by a higher radius and stage loading at a somewhat reduced degree of reaction. Such a stage would sit on the same rotor as described before and it would have a mean radius of $750 \mathrm{~mm}$ at a blade length of $120 \mathrm{~mm}$. For the comparison with the SCOCCC the two-stage subsonic design is chosen because it is the conventional design for heavy-duty gas turbines.

The power turbine is proposed with a strong change of inner radius on a solid shaft. Five stages are necessary for the $50 \mathrm{~Hz}$ design of Fig. 6. The axial outlet speed should be kept at

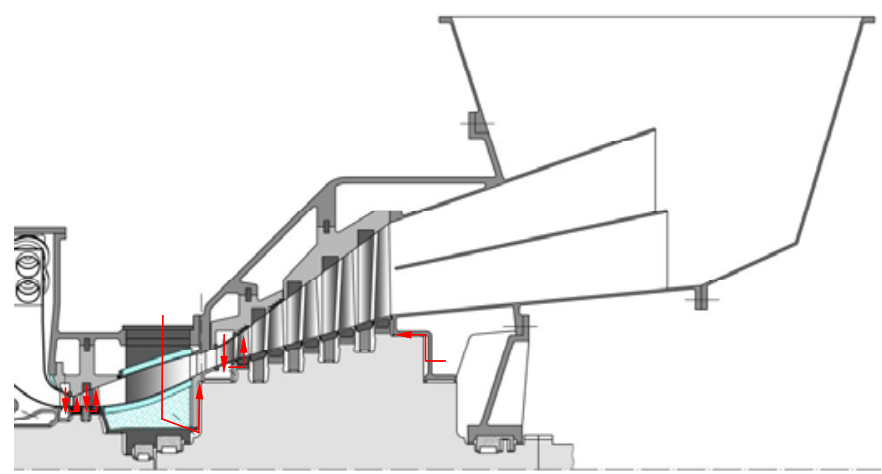

Fig. 6: Design of two-stage HTTC and $50 \mathrm{~Hz}$ HTTP medium value in order to reduce the exhaust loss, to reduce axial diffuser exit length and to facilitate the flow transfer to the HRSG inlet. The design proposed provides last blade lengths of $647 \mathrm{~mm}$ at $2460 \mathrm{~mm}$ inner diameter.

Detailed deliberations on the intermediate bearing casing in its hot environment and on thrust equalization using a steam operated balance piston are given in [2].

\section{Steam turbines:}

The LPST is fed with steam of 0.75 bar and $175^{\circ} \mathrm{C}$. Expanding the steam to a condensation pressure of 0.021 bar leads to a high volume flow. At $50 \mathrm{~Hz}$ a four-flow design with three stages, as shown in Fig. 3, is able to handle this steam flow with excellent efficiency. The last stage is transonic with a blade length of $970 \mathrm{~mm}$.

The HPT is a standard high-speed back-pressure steam turbine of $50 \mathrm{MW}$ power output for which many designs are in the market. A geared type seems to be a superior solution since better flow efficiency and operability due to nozzle boxes and low number of stages with long blades and low leakage loss can be achieved. It can be coupled to the far end of the LPST or can be used to drive a separate smaller electric generator.

Both turbines can be considered as conventional and correspond to the HPT and LPT of a steam turbo set with an intermediate pressure turbine in-between.

\section{Compressors C3 and C4:}

The delivery compressors C3 and C4, which increase the pressure of the working fluid prior to condensation in order to obtain better evaporation conditions for the bottoming steam cycle, are also needed to vent the internal volume before start up. They are two one-stage compressors and are driven by two separate speed-controlled motors.

\section{SCOC-CC turbomachinery}

The thermodynamic calculations allow an estimate of turbomachinery power and dimensions for the SCOC-CC plant based on the same assumptions as for the Graz Cycle. The resulting main parameters and dimensions are given in Table 3. The working fluid contains largely $\mathrm{CO}_{2}$, so that it has significantly lower values of gas constant $(-43 \%)$ and heat capacity (-37\%) compared to the steam rich working fluid of the Graz Cycle. This results in lower sonic velocities and lower enthalpy differences for a given pressure difference.

\section{Compressor C1:}

Despite the much higher mass flow, the inlet and outlet flow volumes are similar to the $\mathrm{C} 1 / \mathrm{C} 2$ conditions. But due to the lower sonic velocity at the compressor inlet $(-33 \%)$ the limit of a maximum tip Mach number of 1.35 leads to a rotational speed of $3000 \mathrm{rpm}$ for this compressor. Therefore a one-shaft design is reasonable with the HTT driving the C1 compressor as well as the generator. Based on the flow parameters stated above, a design with 19 stages is suggested, with an inner diameter of $1070 \mathrm{~mm}$. The hub to tip ratio is 0.5 
Table 3: Turbomachinery Dimensions for a 400 MW SCOC-CC Plant

\begin{tabular}{|l|l|r|r|r|}
\hline & & $\begin{array}{c}\text { HTT- } \\
\mathrm{C}^{*}\end{array}$ & $\begin{array}{c}\text { HTT- } \\
\mathrm{P}^{*}\end{array}$ & $\mathrm{C} 1$ \\
\hline Inlet mass flow & $\mathrm{kg} / \mathrm{s}$ & 565 & 725 & 657 \\
\hline Inlet volume flow & $\mathrm{m} / \mathrm{s}$ & 50 & 180 & 363 \\
\hline Outlet mass flow & $\mathrm{kg} / \mathrm{s}$ & 725 & 737 & 645 \\
\hline Outlet volume flow & $\mathrm{m}^{3} / \mathrm{s}$ & 180 & 1270 & 19.5 \\
\hline Inlet mean diameter D & $\mathrm{m}$ & 1.483 & 1.912 & 1.595 \\
\hline Inlet inner diameter & $\mathrm{m}$ & 1.369 & 1.639 & 1.07 \\
\hline Inlet blade length l & $\mathrm{m}$ & 0.114 & 0.273 & 0.525 \\
\hline Inlet D/l & - & 13 & 7 & \\
\hline Inlet $\mathrm{D}_{\text {in }} / \mathrm{D}_{\text {out }}$ & - & & & 0.5 \\
\hline Outlet mean diameter D & $\mathrm{m}$ & 1.881 & 2.853 & 1.11 \\
\hline Outlet inner diameter & $\mathrm{m}$ & 1.612 & 2.283 & 1.07 \\
\hline Outlet blade length l & $\mathrm{m}$ & 0.269 & 0.57 & 0.04 \\
\hline Outlet D/l & - & 7 & 5 & \\
\hline Outlet $\mathrm{D}_{\text {in }} / \mathrm{D}_{\text {out }}$ & - & & & 0.93 \\
\hline Enthalpy drop & $\mathrm{kJ} / \mathrm{kg}$ & 391 & 439 & 361 \\
\hline Work coefficient & - & 2.2 & 2 & 0.814 \\
\hline Stage number & - & 5 & 3 & 19 \\
\hline Speed & $\mathrm{rpm}$ & 3000 & 3000 & 3000 \\
\hline
\end{tabular}

* HTT compressor turbine and power turbine are physically one turbine.

at the inlet and 0.93 at the exit leading to relatively small blades of $40 \mathrm{~mm}$ for this large diameter. A slightly different design is presented in the ENCAP project [1]. For a $20 \%$ reduced mass flow, the C1 compressor needs 24 stages with a work coefficient of 0.5 for similar hub to tip ratios at the same speed of $3000 \mathrm{rpm}$. Both designs need high stage numbers which bear the risk of deterioration of the meridional flow profile towards the last stages because of endwall boundary layer growth leading to reduced flow efficiency.

In contrast the Graz Cycle compressors have a more favorable hub to tip ratio and a total number of only 13 axial and one radial stages. The intercooler between C1 and C2 interrupts the compression process and thus enables an undisturbed and compact flow profile at the inlet of the C2 compressor. On the other hand, additional pressure losses are caused by the C1 outlet and C2 inlet scroll.

Regarding the operating conditions, the exit flow temperature of the SCOC-CC compressor is below $400^{\circ} \mathrm{C}$ compared to $580^{\circ} \mathrm{C}$ for the $\mathrm{C} 2$ compressor, so that no rotor cooling is necessary. The centrifugal load is only a quart of the $\mathrm{C} 1 / \mathrm{C} 2$ compressors, so that high stresses and expensive materials like titanium or Nimonic can be avoided. But the long and slender rotor may result in rotor dynamics problems.

A further risk for the operation of the $\mathrm{CO}_{2}$ compressor is the inlet working fluid with its steam content at saturation. Flow acceleration there with its temperature decrease can lead to the formation of water droplets which can cause blade erosion.

\section{Turbine HTT:}

The maximum speed of $3000 \mathrm{rpm}$ for the $\mathrm{C} 1$ compressor leads to a one-shaft design for the HTT (compressor turbine + power turbine) running at the same speed. Despite the higher mass flow the volume flows at inlet and exit are similar. The total enthalpy drop is $830 \mathrm{~kJ} / \mathrm{kg}$ compared to $1560 \mathrm{~kJ} / \mathrm{kg}$ for the Graz Cycle. But in the hot section the expansion of a pressure ratio similar to the one of the Graz Cycle HTTC needs five cooled stages compared to two because of the lower speed and thus stage enthalpy drop. Therefore the cooled surface area and thus cooling mass flow demand of the HTT is remarkably higher than for the Graz Cycle. A further reason for the increase of necessary cooling mass flow is that the cooling medium is largely $\mathrm{CO}_{2}$ with a smaller heat capacity than steam (see Eq. (7)). And as third reason, the cooling flow of the hot section has an inlet temperature of $387^{\circ} \mathrm{C}$ compared to a steam temperature of $330^{\circ} \mathrm{C}$ at HPT outlet of the Graz Cycle. So the total cooling flow demand is calculated to $30.5 \%$ of the inlet mass flow to the HTT compared to $13.7 \%$ for the Graz Cycle. About one fourth of this high increase can be attributed to the unfavorable fluid properties of $\mathrm{CO}_{2}$, about one third to a higher cooling flow temperature and the rest to the increased stage number. This higher cooling demand is also the main reason for the high difference in cycle efficiency.

The rotational speed of $3000 \mathrm{rpm}$ leads to a total stage number of 8 compared to 7 for the Graz Cycle, despite of only about half the total enthalpy drop. The inlet diameter is larger than for the Graz Cycle turbine at similar blade length, whereas the outlet inner diameter is slightly smaller at a smaller blade length due to smaller flow volume change. The work coefficient is 2.2 for the first five stages similar to the Graz Cycle HTTC, and 2 for the last three stages as compared to 2.5 for the five stages of the Graz Cycle HTTP.

Cooling is done with nearly pure $\mathrm{CO}_{2}$. The circulating inventory of $\mathrm{CO}_{2}$ is continuously replaced by inflow from the burners and is held constant by separation at the low pressure end. So attention has to be paid on the danger of accumulation of fine particles from soot and ash. There is high risk of deposition of particles on the surfaces of the internal cooling channels of the blades because of the high centrifugal forces, which can lead to clogging of the serpentine passages and the small laser-drilled film cooling holes [25]. On the other hand, the use of steam from an evaporation process in the Graz Cycle allows a high purity of the cooling flow medium.

\section{Steam turbines:}

The steam cycle data of the SCOC-CC plant is very conventional and suitable turbines for this power range are in operation in combined cycle plants world-wide. The high steam volume flow at the exit of the LPT will also demand a fourflow design at $3000 \mathrm{rpm}$.

\section{Start-up:}

The start-up procedure of the SCOC-CC is very similar to a conventional combined cycle plant. It is expected that before start-up the gas turbine cycle is filled with $\mathrm{CO}_{2}$ at 1 bar. During 
start-up additional $\mathrm{CO}_{2}$ has to be sucked in from a storage tank, which has to keep a pressure of 1 bar.

For the Graz Cycle a detailed start-up procedure is given in [2]. An auxiliary steam boiler is needed to provide steam for the start-up.

\section{ECONOMIC EVALUATION}

In [2] an economic evaluation of the Graz Cycle was done resulting in relatively low $\mathrm{CO}_{2}$ mitigation costs of $21-28 \$$ ton $\mathrm{CO}_{2}$. The variation in costs stems from the uncertainty in the costs of oxygen supply. In this work a similar rough evaluation is performed in order to compare the SCOC-CC plant with the Graz Cycle on an economic basis.

The evaluation is based on a comparison with a state-ofthe-art combined cycle power plant of 58\% efficiency. For the economic balance following assumptions are used: 1) The yearly operating hours is assumed at $8500 \mathrm{hrs} / \mathrm{yr}$. 2) The capital charge rate is $12 \% / y r$, which corresponds to an interest rate of 8 $\%$ over a depreciation period of 15 years. 3) Methane fuel costs are $1.3 \mathrm{\$} / \mathrm{kWh}_{\mathrm{th}}$. 4) In order to estimate the investment costs, the power of the main components is compared with the reference plant in Table 4. For the Graz Cycle all components are of same size or smaller (compressor), besides the generator. For the SCOC-CC plant the power of generator, HRSG and steam turbines is higher, the compression and gas turbine power is smaller. So for this rough economic estimate the same total plant costs are assumed for all three plants, i.e. the same specific costs related to $400 \mathrm{MW}$ net output instead to generator power (see Table 5). Development efforts needed especially for HTT and combustor are not considered in the investment costs. 5) Additional investment costs are assumed for the cryogenic air separation unit (ASU), for additional equipment and $\mathrm{CO}_{2}$ compression to 100 bar (see Table 5 with low-cost data according to Göttlicher [26]). 6) The costs of $\mathrm{CO}_{2}$ transport and storage are not considered because they depend largely on the site of a power plant.

Table 6 shows the result of the economic evaluation. Compared to the reference plant, the capital costs are about 70 $\%$ higher for the Graz Cycle and $73 \%$ for the SCOC-CC by

Table 4: Comparison of equipment size for a plant of $400 \mathrm{MW}$ net power output

\begin{tabular}{|l|l|l|l|}
\hline & $\begin{array}{l}\text { Convent. } \\
\text { CC plant }\end{array}$ & $\begin{array}{l}\text { Graz } \\
\text { Cycle }\end{array}$ & $\begin{array}{l}\text { SCOC- } \\
\text { CC }\end{array}$ \\
\hline $\begin{array}{l}\text { turbine of "gas } \\
\text { turbine"/ HTT }\end{array}$ & $667 \mathrm{MW}$ & $623 \mathrm{MW}$ & $557 \mathrm{MW}$ \\
\hline $\begin{array}{l}\text { compressor of "gas } \\
\text { turbine"/C1+C2+C3+C4 }\end{array}$ & $400 \mathrm{MW}$ & $241 \mathrm{MW}$ & $235 \mathrm{MW}$ \\
\hline $\begin{array}{l}\text { steam turbines/ } \\
\text { HPT+LSPT }\end{array}$ & $133 \mathrm{MW}$ & $120 \mathrm{MW}$ & $190 \mathrm{MW}$ \\
\hline HRSG & $380 \mathrm{MW}$ & $360 \mathrm{MW}$ & $461 \mathrm{MW}$ \\
\hline Generator & $400 \mathrm{MW}$ & $487 \mathrm{MW}$ & $495 \mathrm{MW}$ \\
\hline
\end{tabular}

Table 5: Estimated specific investment costs

\begin{tabular}{|c|c|c|c|}
\hline Component & $\begin{array}{c}\text { Scale } \\
\text { parameter }\end{array}$ & & $\begin{array}{l}\text { Specific } \\
\text { costs }\end{array}$ \\
\hline \multicolumn{4}{|l|}{ Reference Plant } \\
\hline Investment costs & Electric power & $\$ / \mathrm{kW}_{\mathrm{el}}$ & 414 \\
\hline \multicolumn{4}{|l|}{ Graz Cycle Plant } \\
\hline Plant investment costs & Electric power & $\$ / \mathrm{kW}_{\mathrm{el}}$ & 414 \\
\hline Air separation unit [26] & $\mathrm{O}_{2}$ mass flow & $\begin{array}{l}\$ /(\mathrm{kg} \\
\left.\mathrm{O}_{2} / \mathrm{s}\right)\end{array}$ & 1500000 \\
\hline $\begin{array}{l}\text { Other costs (Piping, } \\
\mathrm{CO}_{2} \text {-Recirc.) [26] }\end{array}$ & $\mathrm{CO}_{2}$ mass flow & $\begin{array}{c}\$ /(\mathrm{kg} \\
\left.\mathrm{CO}_{2} / \mathrm{s}\right)\end{array}$ & 100000 \\
\hline $\begin{array}{l}\mathrm{CO}_{2} \text {-Compression } \\
\text { system [26] }\end{array}$ & $\mathrm{CO}_{2}$ mass flow & $\begin{array}{l}\$ /(\mathrm{kg} \\
\left.\mathrm{CO}_{2} / \mathrm{s}\right)\end{array}$ & 450000 \\
\hline
\end{tabular}

considering the additional components for $\mathrm{O}_{2}$ generation and $\mathrm{CO}_{2}$ compression. So they contribute mostly to the difference in costs of electricity (COE). The fuel costs have the major influence on the $\mathrm{COE}$, and there is the largest difference between both $\mathrm{CO}_{2}$ free cycles due to the difference in efficiency. The O\&M costs are assumed $15 \%$ higher for both plants due to the operation of additional equipment.

Based on these assumptions, the increased COE compared to the reference plant is $0.72 \$ / \mathrm{kWh}_{\mathrm{el}}$ for the Graz Cycle and $0.90 \mathrm{\$} / \mathrm{kWh}_{\mathrm{el}}$ for the SCOC-CC. This results in mitigation costs of 21.0 \$ and 26.2 \$ per ton of $\mathrm{CO}_{2}$ avoided, if $\mathrm{CO}_{2}$ liquefaction is considered. Both values are clearly below a threshold value of $30 \$$ ton showing the economic potential of both cycles, with some advantages for a Graz Cycle plant.

Table 6: Economic comparison for a $400 \mathrm{MW}$ plant

\begin{tabular}{|c|c|c|c|}
\hline & $\begin{array}{l}\text { Refer. } \\
\text { plant }\end{array}$ & $\begin{array}{c}\text { GC } \\
\text { plant }\end{array}$ & \begin{tabular}{|l|} 
SCOC- \\
CC plant
\end{tabular} \\
\hline Plant capital costs $\left[\$ / \mathrm{kW}_{\mathrm{el}}\right]$ & 414 & 414 & 414 \\
\hline Addit. capital costs $\left[\$ / \mathrm{kW}_{\mathrm{el}}\right]$ & & 288 & 300 \\
\hline $\mathrm{CO}_{2}$ emitted $\left[\mathrm{kg} / \mathrm{kWh} \mathrm{h}_{\mathrm{el}}\right]$ & 0.342 & 0.0 & 0.0 \\
\hline Net plant efficiency [\%] & 58.0 & 53.09 & 49.75 \\
\hline COE f. plant amort. [ $\left.\mathrm{\Phi} / \mathrm{kWh}_{\mathrm{el}}\right]$ & 0.58 & 0.99 & 1.01 \\
\hline COE due to fuel $\left[\mathrm{\&} / \mathrm{kWh}_{\mathrm{el}}\right]$ & 2.24 & 2.45 & 2.61 \\
\hline COE due to O\&M $\left[\mathrm{\Phi} / \mathrm{kWh}_{\mathrm{el}}\right]$ & 0.7 & 0.8 & 0.8 \\
\hline Total COE $\quad\left[\mathbf{c} / \mathbf{k W h} \mathbf{h}_{\mathrm{el}}\right]$ & 3.52 & 4.24 & 4.42 \\
\hline \multicolumn{4}{|l|}{ Comparison } \\
\hline Differential COE $\left[\mathbf{c} / \mathbf{k W h} \mathrm{h}_{\mathrm{el}}\right]$ & & 0.72 & 0.90 \\
\hline Mitigation costs [\$/ton $\left.\mathrm{CO}_{2}\right]$ & & 21.0 & 26.2 \\
\hline
\end{tabular}

The results of the economic study depend mainly on the assumptions about investment costs, fuel costs and capital charge rate. A cost sensitivity analysis performed in [5] showed that a variation of the capital costs has the main influence on the economics, since they contribute most to the mitigation costs. But unfortunately there is a large uncertainty of these costs (e.g. the cost estimates of the most expensive additional unit, the ASU, vary between 230 and $400 \$ / \mathrm{kW}_{\mathrm{el}}$ ) and the values presented above can be regarded as a lower limit until a 
more cost-saving method of oxygen generation, e.g. by membranes, will be developed.

\section{PATHWAY TO COMMERCIAL DEMONSTRATION}

The feasibility of oxy-fuel power generation from natural gas was demonstrated by Clean Energy Systems (CES) in their 5 MW Kimberlina test plant in Bakersfield, California [27]. In Norway their technology shall be used for a demonstration plant of 50-70 MW within the ZENG project [28]. But in order to achieve a good efficiency the CES technology needs a HTT nearly identical to the one of the Graz Cycle. Although many design deliberations for the HTT were made by the authors, the final design and building can only be done by a large gas turbine manufacturer. Within a DOE program [29] Siemens Westinghouse investigates a HTT-type gas turbine, but a pilot turbine cannot be expected before 2015. In the meantime it is planned to adopt expanders of standard gas turbines for noncooled low-temperature operation in the ZENG project.

The authors expect that the Graz Cycle will be a beneficiary of these activities. So the ZENG project will demonstrate most of the components needed and thus help to pave the way towards a Graz Cycle plant. There is also current interest of end-users but they depend on a manufacturer ready to get in. So under the current circumstances, work towards a demonstration plant will not start before 2010 .

\section{CONCLUSIONS}

Within the European project ENCAP several oxy-fuel power cycles were compared based on their thermodynamic efficiencies and technical maturity. The Graz Cycle and the SCOC-CC emerged as two very promising variants, the Graz Cycle due to its high efficiency and the SCOC due to its relatively low complexity at a slightly smaller efficiency.

In this work the ENCAP study is repeated for the SCOCCC and a modified Graz Cycle variant as presented at the ASME IGTI conference 2006 [2]. Both oxy-fuel cycles were thermodynamically investigated and a layout of the main components of both cycles was presented and discussed thoroughly. Contrary to the ENCAP study the Graz Cycle achieves a remarkably higher efficiency, mainly because of the very high cooling demand of the SCOC-CC HTT. This is a result of the less favorable properties of the working fluid consisting mainly of $\mathrm{CO}_{2}$.

The layout of the turbomachinery showed that both cycles need new designs for the HTT and the compressors because of their unusual working fluids. The low sonic velocity of $\mathrm{CO}_{2}$ leads to a rotational speed of $3000 \mathrm{rpm}$ for all SCOC-CC turbomachinery. So more stages for the compressor and the HTT as compared to the Graz Cycle turbomachines are needed despite a much lower enthalpy drop. On the other hand, the SCOC-CC compressor has the advantage of a lower operating temperature. The cooling of the SCOC-CC HTT is done with working fluid in contrast to steam for the Graz Cycle HTT. Since the combustion process can lead to the accumulation of soot and ash in the working fluid, there is high risk of clogging of the internal cooling channels and film cooling holes. All turbomachinery of both cycles is regarded as feasible, no decisive advantage for the SCOC-CC components was seen contrary to the ENCAP study.

In a comparative economical analysis the Graz Cycle power plant showed lower $\mathrm{CO} 2$ mitigation costs of $5 \$$ ton $\mathrm{CO}_{2}$ mainly due to the higher efficiency of the Graz Cycle scheme.

So the authors believe that their Graz Cycle is a very efficient and feasible solution for a future CCS scheme. And its possibility to use syngas from coal gasification makes it also attractive for an emission-free use of coal as a relatively cheap and long-term available fuel [30].

\section{REFERENCES}

[1] Franco, F., Mina, T., Woolatt, G., Rost, M., Bolland, O., 2006, "Characteristics of Cycle Components for CO2 Capture”, Proceedings of $8^{\text {th }}$ International Conference on Greenhouse Gas Control Technologies, Trondheim, Norway

[2] Jericha, H., Sanz, W., Göttlich, E., 2006, "Design Concept for Large Output Graz Cycle Gas Turbines", ASME Paper GT2006-90032, ASME Turbo Expo 2006, Barcelona, Spain

[3] Haege, K., 2006, www.zero-emissionplatform.eu

[4] Brandels, L., 2006, www.encapco2.org

[5] Sanz, W., Jericha, H., Luckel, F., Heitmeir, F., 2005 , "A further step Towards a Graz Cycle Power Plant for $\mathrm{CO}_{2}$ Capture", ASME Paper GT2005-68456, ASME Turbo Expo 2005, Reno-Tahoe, USA

[6] SimTech Simulation Technology, 2003, "IpsePro Overview", http://www.simtechnology.com/IPSEpro

[7] Wagner, W., Kruse, A., "Properties of Water and Steam", Springer-Verlag Berlin Heidelberg New York, 1998

[8] Span, R., Wagner, W., 1996, "A New Equation of State for Carbon Dioxide Covering the Fluid Region from the Triple-Point Temperature to $1100 \mathrm{~K}$ at Pressures up to 800 MPa", Journal of Physical and Chemical Reference Data, Vol. 25, No. 6, pp. 1509-1596

[9] Jericha, H., Lukasser, A., Gatterbauer, W., 2000, "Der "Graz Cycle" für Industriekraftwerke gefeuert mit Brenngasen aus Kohle- und Schwerölvergasung" (in German), VDI Berichte 1566, VDI Conference Essen, Germany

[10] Sanz, W., Jericha, H., Moser, M., Heitmeir, F., 2004, "Thermodynamic and Economic Investigation of an Improved Graz Cycle Power Plant for $\mathrm{CO}_{2}$ Capture", ASME Paper GT2004-53722, ASME Turbo Expo 2004, Vienna, Austria, Journal of Engineering for Gas Turbines and Power, Vol. 127, Oct. 2005, pp. 765-772

[11] Jordal, K., Bolland, O., Klang, A., 2003, "Effects of Cooled Gas Turbine Modelling for the Semi-Closed O2/ $\mathrm{CO}_{2}$ Cycle with $\mathrm{CO}_{2}$ Capture", ASME Paper 2003-GT38067, ASME Turbo Expo 2003, Atlanta, USA

[12] Louis, J.F., 1977, "Systematic Studies of Heat Transfer and Film Cooling Effectiveness”, in AGARD CP 229 
[13] Jericha, H., 1985, "Efficient Steam Cycles with Internal Combustion of Hydrogen and Stoichiometric Oxygen for Turbines and Piston Engines", CIMAC Conference Paper, Oslo, Norway

[14] Jericha, H., Sanz, W., Woisetschläger, J., Fesharaki, M., 1995, " $\mathrm{CO}_{2}$ - Retention Capability of $\mathrm{CH}_{4} / \mathrm{O}_{2}$ - Fired Graz Cycle", CIMAC Conference Paper, Interlaken, Switzerland

[15] Jericha, H., Fesharaki, M., 1995, "The Graz Cycle $1500^{\circ} \mathrm{C}$ Max Temperature Potential $\mathrm{H}_{2}-\mathrm{O}_{2}$ Fired $\mathrm{CO}_{2}$ Capture with $\mathrm{CH}_{4}-\mathrm{O}_{2}$ Firing", ASME Paper 95-CTP-79, ASME Cogen-Turbo Power Conference, Vienna, Austria

[16] Jericha, H., Göttlich, E., 2002, "Conceptual Design for an Industrial Prototype Graz Cycle Power Plant", ASME Paper 2002-GT-30118, ASME Turbo Expo 2002, Amsterdam, The Netherlands

[17] Jericha, H., Göttlich, E., Sanz,W., Heitmeir, F., 2003, "Design Optimisation of the Graz Cycle Prototype Plant", ASME Paper 2003-GT-38120, ASME Turbo Expo 2003, Atlanta, USA, Journal of Engineering for Gas Turbines and Power, Vol. 126, Oct. 2004, pp. 733-740

[18] Heitmeir, F., Sanz,W., Göttlich, E., Jericha, H., 2003, "The Graz Cycle - A Zero Emission Power Plant of Highest Efficiency", XXXV Kraftwerkstechnisches Kolloquium, Dresden, Germany

[19] Jericha, H., Sanz,W., Pieringer, P., Göttlich, E., Erroi, P., 2004, "Konstruktion der ersten Stufe der HTTGasturbine für den Graz Cycle" (in German), VDI Berichte 1857, VDI Tagung "Stationäre Gasturbinen: Fortschritte und Betriebserfahrungen", Leverkusen

[20] Jericha, H., Sanz, W., 2001, "Wärmekraftanlagen mit Verbrennung von Kohlenwasserstoffen mit reinem Sauerstoff zur Stromerzeugung bei Rückhaltung von Kohlendioxyd" (in German), Austrian Patent No. AT 409 162 B

[21] Göttlich, E., Innocenti, L., Vacca, A., Sanz, W., Woisetschläger, J., Facchini, B., Jericha, H., Rossi, E.,
2004, "Measurement and Simulation of a Transonic Innovative Cooling System (ICS) for High-Temperature Transonic Gas Turbine Stages", ASME Paper GT200453712, ASME Turbo Expo 2004, Vienna

[22] IEA, 2004, "Prospects for $\mathrm{CO}_{2}$ Capture and Storage“, IEA/OECD, Paris, France

[23] Jericha, H., Sanz, W., Göttlich, E., 2006, "Gasturbine mit CO2-Rückhaltung - 490 MW (System Graz Cycle)“, (in German), VDI Tagung "Stationäre Gasturbinen: Fortschritte und Betriebserfahrungen", Leverkusen

[24] Hennecke, D. K. , 1997, "Transsonik-VerdichterTechnologien für stationäre Gasturbinen und Flugtriebwerke" (in German), Festschrift zum Jubiläum 100 Jahre Turbomaschinen TU-Darmstadt, published by TU-Darmstadt, Darmstadt, Germany

[25] König, P., Rossmann, A., 1999, "Ratgeber für Gasturbinenbetreiber" (in German), Vulkan-Verlag, Essen

[26] Göttlicher, G., 1999, "Energetik der Kohlendioxidrückhaltung in Kraftwerken" (in German), Fortschritt-Berichte VDI, Reihe 6, Energietechnik, Nr. 421. Düsseldorf: VDI Verlag

[27] Anderson, R.E., Bischoff, R.W., 2006, "Durability and Reliability Demonstration of a Near-Zero-Emission GasFired Power Plant", PIER Final Project report (www.cleanenergystems.com)

[28] Hustad, C.-W., Tronstad, I., Anderson, R.E., Pronske, K.L., Viteri, F., 2005, "Optimization of Thermodynamically Efficient Nominal 40 MW Pilot and Demonstration Power Plant in Norway", ASME Paper GT2005-68640, ASME Turbo Expo 2005, Reno-Tahoe, USA

[29] US Dept. of Energy, 2005, http://www.fossil.energy. gov/news/techlines/2005/tl_enabling_turbines_awards.ht $\mathrm{ml}$

[30] Simmons, H., 2005, "The Importance of Turbo Expo", Mechanical Engineering, Vol. 127, No. 12 


\section{APPENDIX}

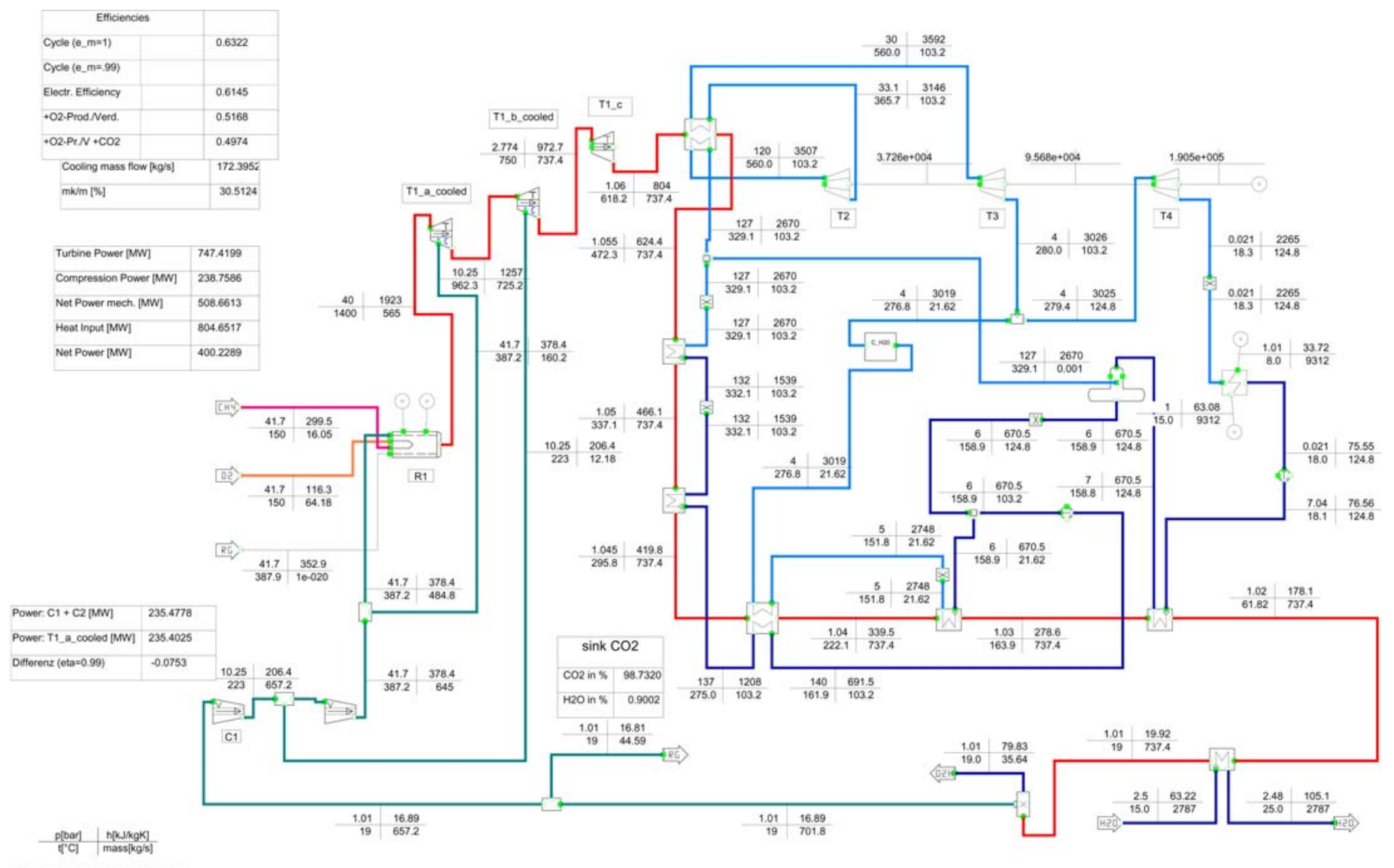

Fig. 7: Detailed thermodynamic cycle data of a 400 MW SCOC-CC Power Plant fired with methane 